\title{
MICROSCOPICALLY BASED CALIBRATION OF THE COHESIVE MODEL
}

\author{
JaRoseaw GaŁKIEWICZ
}

Kielce University of Technology, Kielce, Poland

e-mail: jgalka@tu.kielce.pl

\begin{abstract}
In this paper, the calibration of a cohesive zone model in front of a crack is presented. It is based on the behavior of a cell containing a void. The sizes of the cell and the void are assumed to be representative for a chosen material. The cell is located at the crack tip. The loading conditions of the cell take into account the constraint level ahead of the crack tip. The influence of the constraint on the cohesive model parameters is investigated.
\end{abstract}

Keyword: fracture mechanics, cohesive model, voids growth, micromechanics, constraint

\section{Introduction}

The cohesive model is based on Barenblatt's model of the cohesive zone in front of a crack (Barenblatt, 1959). He assumed an autonomic, specific for any material, zone in front of a crack tip where the material is not allowed to fracture due to cohesive forces. In Barenblatt's model, distribution of the cohesive forces was unknown. The length of the cohesive zone was also unknown. It was assumed to be very short. Panasyuk (1968) and Dugdale (1960) solved the problem of the unknown length of the cohesive zone assuming the stress distribution within it. In fact, they assumed a constant value of the cohesive stress which was equal to the yield stress of a material. However, Dugdale called this zone the plastic zone.

The cohesive model is a simple and effective tool to analyze fractures. However, the simplicity follows from the fact that all processes taking place in front of the crack tip are hidden in a function describing the distribution of the cohesive forces. The behavior of the cohesive zone has been investigated by many authors (e.g. Xia and Shih, 1995a,b; Brocks et al., 2003). In those papers, Gurson's model (Gurson, 1977; Tvergaard, 1981; Tvergaard and Needleman, 1984) was used. Gurson's model takes into account the evolution of voids during deformation of a material.

The main drawback of both models is a large number of parameters that must be either assumed or computed. As a result, the calibration procedure is complicated. In the case of the cohesive model, a tensile test can be used to evaluate the parameters characterizing the macroscopic properties of a material (i.e. yield strength $\sigma_{0}$, Young's modulus $E$, Poisson's ratio $\nu$, Ramberg-Osgood parameters $\alpha, n)$. Unfortunately, there is no unique procedure to assess the parameters of a cohesive zone. Numerous papers show that the shape of the traction-separation function is unimportant (Tvergaard and Hutchinson, 1992). The main parameters that influence the result are: work of separation $\Gamma_{n}$, maximum traction of the cohesive element $\sigma_{\text {max }}$ and, related to later quantity, the separation between the cohesive surfaces when the traction reaches the zero value. Usually, the work of separation is considered to be fracture toughness under small scale yielding conditions (Xia and Shih, 1995a,b). The maximum traction is usually expressed as a multiple of the yield stress (Xia and Shih, 1995a,b). The problem of the calibration of the cohesive model parameters has been discussed many times ( $\mathrm{Li}$ and Ward, 1989; Tvergaard and Hutchinson, 1992; Scheider and Brocks, 2003; Cornec et al., 2003; Sorensen and Jacobsen, 2003) 
however, these attempts have not connected the cohesive model parameters directly with the processes taking place in the microstructure of a material in front of the crack tip.

Gurson's model requires considerable effort during calibration. Apart from the tensile parameters, other quantities are hard to evaluate, such as Tvergaard's coefficients $q_{1}, q_{2}, q_{3}$ (Tvergaard ,1981), void volume fractions in the cell, namely: initial $f_{0}$, of void nucleating particles $f_{N}$, critical $f_{c}$, final $f_{f}$, and statistical parameters describing strains at the moment of initiation of the fast nucleation of voids (the mean void nucleation burst strain $\varepsilon_{N}$ and the corresponding standard deviation $S_{N}$ (Tvergaard and Needleman, 1984)).

Faleskog et al. (1998) and Gao et al. (1998) developed a new method of calibration for Tvergaard's coefficients $q_{1}$ and $q_{2}$. The method directly connects Gurson's model with the material microstructure and its evolution under loading conditions. They use the representative volume cell containing one void. The results achieved with this model are compared with the results achieved using the same representative volume cell but made of Gurson's material. In this method, the assumed size of the material cell is based on the spacing of large inclusions. The size of the void is related to the initial void fraction $f_{0}$. The cell loading (Fig. 1) reflects the high constraint ahead of the crack tip in the plane strain conditions (O'Dowd et al., 1995). In the second model, the cell is filled with Gurson's material, in which the coefficients $q_{1}$ and $q_{2}$ are adjusted to obtain the same response of both models.

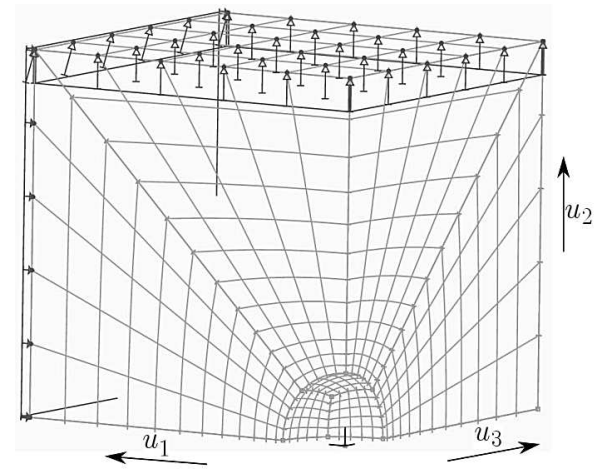

Fig. 1. Loading of a cell

\section{Modeling of the void}

In this paper, Faleskog, Gao and Shih's idea (Faleskog et al., 1998) has been adopted to calibrate the cohesive model. One cell is filled with a continuum characterized by classical tensile properties. It is adjusted to the cohesive element which is located in a plane in front of the crack. Deformation of this sandwich-like model (Fig. 2b) is compared with deformation of the cell containing the void (Fig. 2a). Both models are loaded by displacement applied to the cell faces according to Fig. 1. The values of displacements depend on the constraint level ahead of the crack tip. The parameters of the cohesive element are modified to obtain similar stress-strain curves for the $x_{2}$ direction for both models.

The cell size and the tensile parameters correspond to the material used by Faleskog et al. (1998) and Gao et al. (1998). It is a low strength, high hardening pressure vessel steel (2.25 $\mathrm{Cr} 1 \mathrm{Mo})$ used for chemical reactors. The yield strength is $210 \mathrm{MPa}$ and the strain hardening exponent $n$ is 5 .

The cell size $(D=300 \mu \mathrm{m})$ is estimated according to the average spacing between the large inclusions. The initial void fraction is set to 0.004 . This value follows from the average initial size of the inclusions. 
(a)

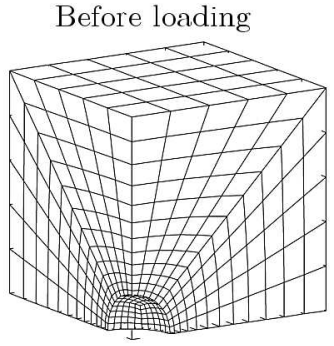

(b)

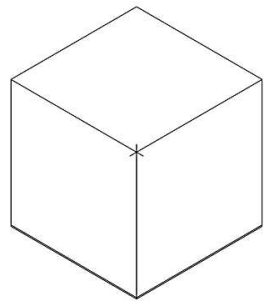

After loading
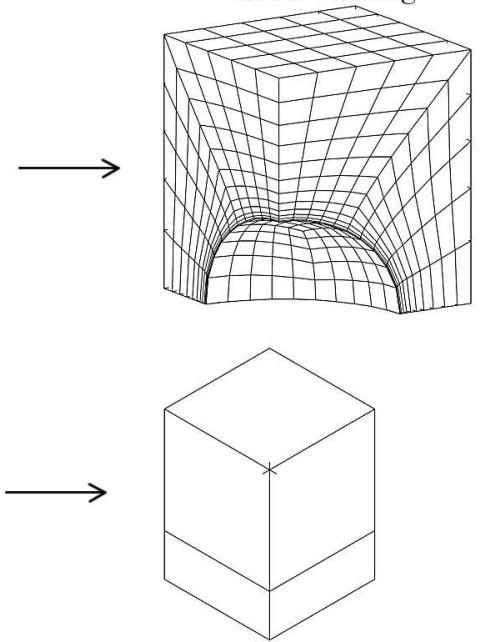

Fig. 2. Geometry of equivalent models: (a) model with the void; (b) model with the cohesive element

\section{Boundary conditions}

The elementary cell is loaded by displacement applied to its faces, as in Fig. 1. Because the cell is located ahead of the crack tip in the plane strain dominated area, it is reasonable to assume that the cell thickness during loading does not change. Displacements applied at each face depend on the stress triaxiality induced by the geometry of the structural member which contains the crack (O'Dowd et al., 1995). The modified boundary layer approach has been used to calculate the constraints, represented by the $T$-stress. The $T$-stress enters the boundary conditions applied at the outer ring (Al-Ani and Hancock, 1991)

$$
\begin{aligned}
& u_{1}=\frac{K}{E}(1+\nu) \sqrt{\frac{r}{2 \pi}} \cos \frac{\theta}{2}\left(\kappa-1+2 \sin ^{2} \frac{\theta}{2}\right)+\left(1-\nu^{2}\right) \frac{T}{E} r \cos \theta \\
& u_{2}=\frac{K}{E}(1+\nu) \sqrt{\frac{r}{2 \pi}} \sin \frac{\theta}{2}\left(\kappa+1-2 \cos ^{2} \frac{\theta}{2}\right)-\nu(1+\nu) \frac{T}{E} r \sin \theta
\end{aligned}
$$

where $K$ is the stress intensity factor, $r$ and $\theta$ are coordinates in the polar coordinate system with the origin located at the crack tip, $T$ is the second term in Williams' solution (Williams,1957), $\kappa=3-4 \nu$.

The level of the constraint influences the ratio $R=u_{1} / u_{2}$ of displacements applied at the cell faces when $u_{3}=0$ due to the plane strain condition ahead of the crack tip (Fig. 1). A regular rectangular grid has been used (Fig. 3). The size of the finite element net in the crack plane is equivalent to the material cell with a symmetry axis in the crack plane.

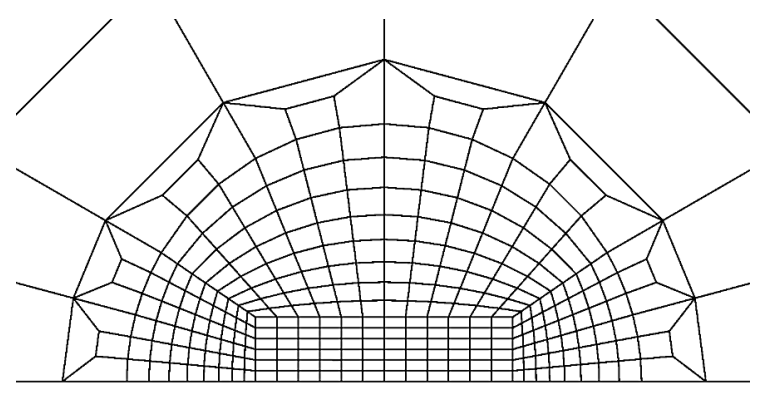

Fig. 3. Finite element grid in the neighborhood of the crack tip

The relation between $T$ and the average value of the $R$-ratio for the first four cells ahead of the crack tip has been computed and selected results are listed in Table 1. 
Table 1. Relation between $R$ and $T$

\begin{tabular}{|c|c|}
\hline$T / \sigma_{0}$ & $R$ \\
\hline \hline+0.5 & -0.15 \\
\hline 0.0 & -0.30 \\
\hline-0.5 & -0.55 \\
\hline-1.0 & -0.78 \\
\hline
\end{tabular}

Graphical representation of the data in Table 1 is shown in Fig. 4.

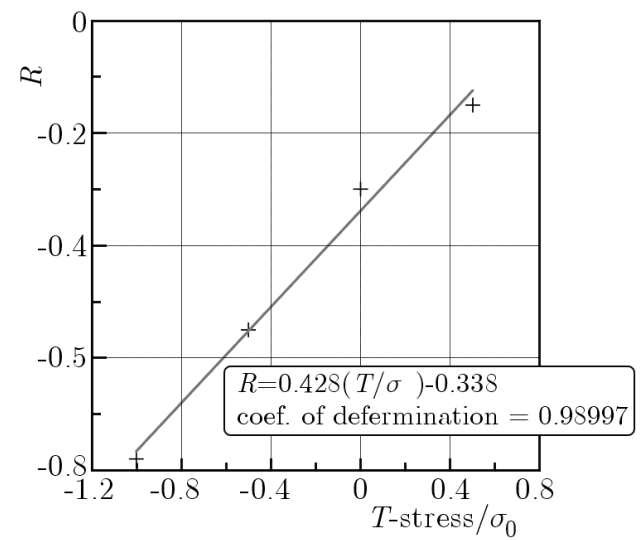

Fig. 4. Changes in the $R$-ratio

As shown in Fig. 4, the $R$-ratio increases almost linearly with the $T$-stress.

\section{Dependence of the cell behavior on the $R$-ratio}

The numerical simulations have been performed using different levels of constraints, represented by the $R$-ratio, listed in Table 1 . In each case, the cell loading is interrupted when the ratio $u_{2} / D=0.15$, where $D$ is the cell size. At this loading, the relative volume of the void in the cell assumed the final value $f_{f}$ for the high level of constraint, $T=0$. It was assumed by Gao et al. (1998) that $f_{f}=0.1$. The results of computations are shown in Fig. 5.

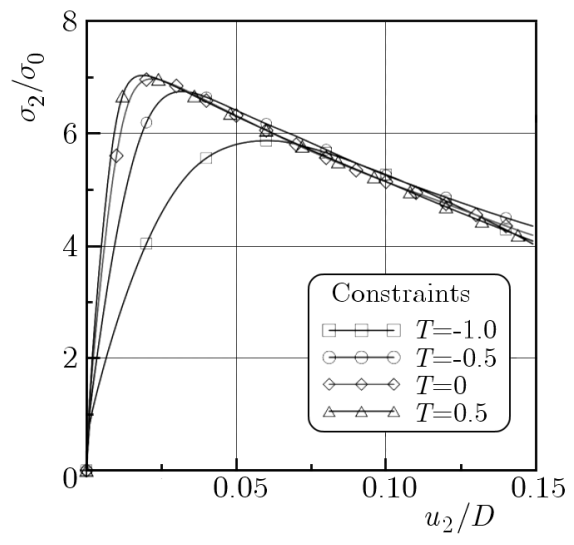

Fig. 5. Element deformation at different levels of constraints

A high level of the constraint results in a high value of the stress maximum. In Fig. 6, the sizes of the voids for different levels of constraints are presented at the critical moment. 
(a)

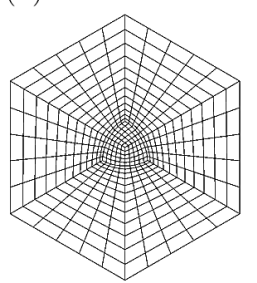

(b)

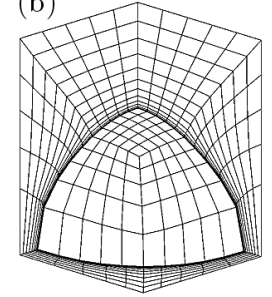

(c)

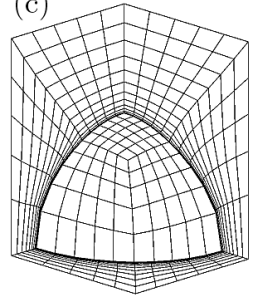

(d)

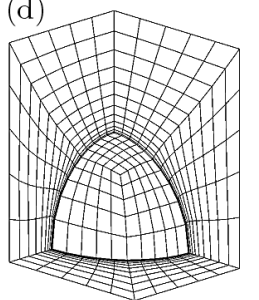

(e)

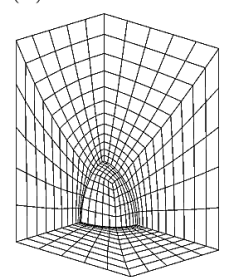

Fig. 6. Voids in the elementary cell: (a) initial size, (b) void size at $T=0.5$, (c) void size at $T=0.0$, (d) void size at $T=-0.5$, (e) void size at $T=-1.0$

The void volume fraction at the final loading for different constraint levels is summarized in Table 2 .

Table 2. The void volume fraction at $u_{2} / D=0.15$ and different constraint levels

\begin{tabular}{|c|c|}
\hline$T / \sigma_{0}$ & $f_{f}$ \\
\hline \hline+0.5 & 0.1120 \\
\hline 0.0 & 0.0905 \\
\hline-0.5 & 0.0523 \\
\hline-1.0 & 0.0170 \\
\hline
\end{tabular}

It is worth noting that at the low stress triaxiality level, the void volume fraction does not reach the critical value at which the cell loses carrying capacity. In such a case, the void volume fraction achieves its maximum value during loading. For $T=-0.5$, the maximum void volume fraction is 0.087 at $u_{2} / D=0.42$ (the applied load is greater than in this paper) and for $T=-1.0$ the maximum void volume fraction is 0.0178 at $u_{2} / D=0.19$.

\section{Calibration of the cohesive model}

The most important parameters of the cohesive model are the maximum cohesive stress and work of separation. The results shown in Sections 2-4 are used to determine these two parameters, assuming the cohesive law proposed by Park, Paulino and Roesler (PPR) (Park et al., 2009). The cell shown in Fig. $2 \mathrm{~b}$ can be considered to be two nonlinear springs in series. The tensile properties of one element are known. They are the tensile properties of steel. The properties of the cohesive element must be selected in such a way that the total response of these two elements is similar to the behavior of the cell containing the void, and finally, the force-displacement curves for the whole specimen and for the numerical model of the specimen are close to each other.

First, the maximum stress in the PPR model has been assumed to be equal to that shown in Fig. 5, taking into account the stress triaxiality, see Fig. 7 and Table 3; the lower the stress triaxiality, the lower the maximum stress level.

Table 3. Maximum traction of the cohesive element

\begin{tabular}{|c|c|}
\hline$T / \sigma_{0}$ & $\sigma_{\max } / \sigma_{0}$ \\
\hline \hline+0.5 & 7.03 \\
\hline 0.0 & 7.00 \\
\hline-0.5 & 6.75 \\
\hline-1.0 & 5.87 \\
\hline
\end{tabular}

To compute the cohesion energy, the modified bisection method has been used. As the input parameter, the work of separation has been used. The influence of this parameter on the square 


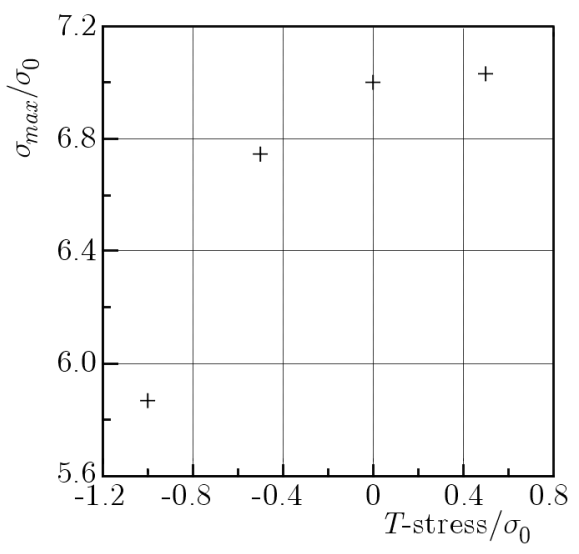

Fig. 7. Influence of constraint on $\sigma_{\max }$

sum of the differences between the obtained curve and the curve selected from Fig. 5 is analyzed. The obtained cohesive energies for different levels of stress triaxiality are presented in Table 4 and Fig. 8.

Table 4. Work of separation $\Gamma_{n}$ for selected $T$-stress levels

\begin{tabular}{|c|c|}
\hline$T / \sigma_{0}$ & $\Gamma_{n}[\mathrm{kN} / \mathrm{m}]$ \\
\hline \hline+0.5 & 88 \\
\hline 0.0 & 74 \\
\hline-0.5 & 42 \\
\hline-1.0 & 5.42 \\
\hline
\end{tabular}

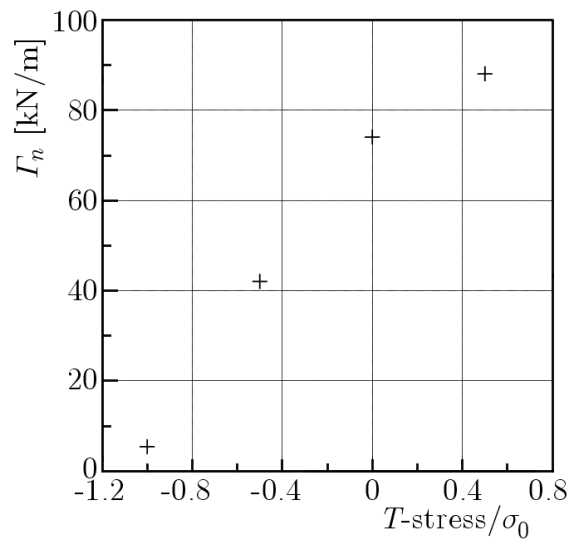

Fig. 8. Influence of constraints on cohesive energy

For negative $T$-stresses, the change in cohesive energy with $T$-stress values is almost linear. For positive values of the $T$-stresses, the increase in $\Gamma_{n}$ is slower. It is worth noting the very low value of the work of separation for low constraints. The cohesive energy for $T=-1.0$ is ten times lower than this value for $T=0$. It should be pointed out that the work of separation is only a part of the energy dissipated in the fracture process.

\section{Application}

Using the data provided by Gao et al. (1998), a simulation of the loading process of a threepoint-bend specimen containing a crack has been performed. The ADINA 8.9.2 system has been 
applied. The material of the specimen is pressure vessel steel $(2.25 \mathrm{Cr} 1 \mathrm{Mo})$. The width of the specimen is $50 \mathrm{~mm}$ and the initial crack length is $30 \mathrm{~mm}$. The ADINA code uses the cohesive model with bilinear relation between the tractions and the displacement developed by Turon et al. (2006). The bilinear law is the most commonly used due to its simplicity. In this case, to define the cohesive model, one must define the maximum traction and cohesive energy only, i.e. two main parameters describing the behavior of cohesive elements. This model has also an advantage over the PPR model that the slope of the traction-separation curve depends only on the external material properties.

Since $a / W=0.6$, it has been assumed that the constraint level is high. The cohesive parameters are assumed for $T=0.0\left(\Gamma_{n}=74 \mathrm{kN} / \mathrm{m}\right.$ and $\left.\sigma_{\max }=1470 \mathrm{MPa}\left(7 \sigma_{0}\right)\right)$. The results of the simulation are presented in Fig. 9.
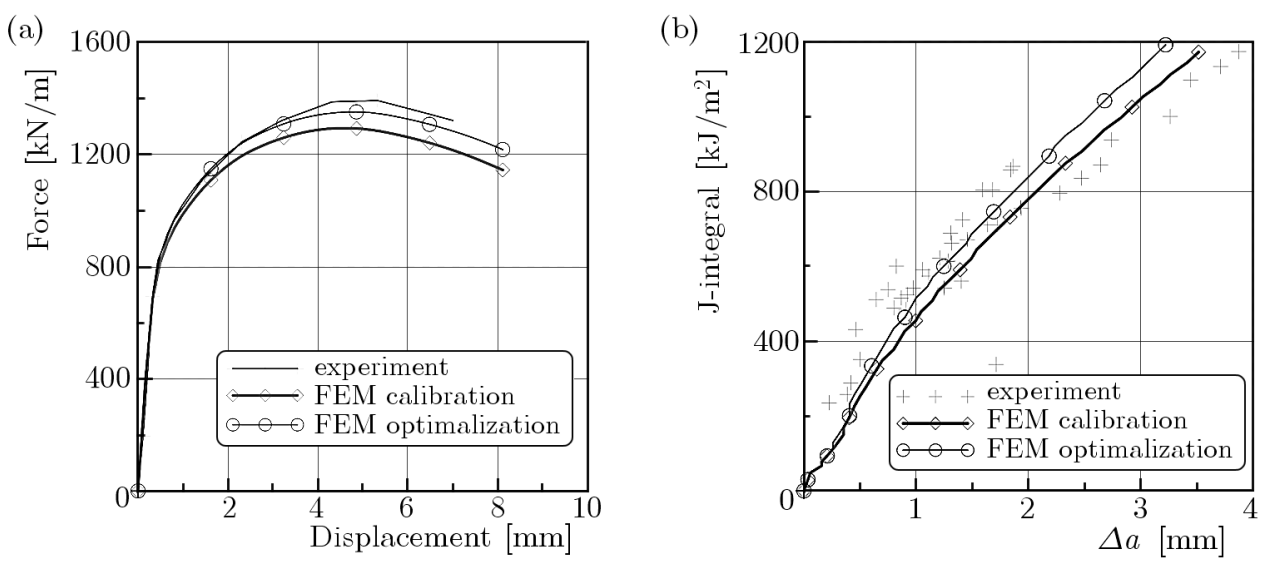

Fig. 9. Results of the three-point bend test and numerical simulation; (a) force-load-point-displacement, (b) $\mathrm{J} R$-curve

Usually, the parameters of the cohesive model are approximated in two stages. In the first, according to the applied procedure, the initial values of the parameters are introduced and then, in the second stage, they are validated or optimized (Cornec et al., 2003; Scheider et al., 2006) to approach the experimental data in the simulations. Figure 9 presents the results of the simulation for similar materials defined by the yield strength equal to $220 \mathrm{MPa}, \Gamma_{n}=73 \mathrm{kN} / \mathrm{m}$ and $\sigma_{\max }=1554 \mathrm{MPa}\left(7.4 \sigma_{0}\right)$.

\section{Conclusions}

It is shown that the parameters of the cohesive model can be calibrated in the same manner as in Gurson's model. The results obtained indicate that the stress triaxiality strongly influences the cohesive model parameters and the energy dissipation process. A low constraint promotes dissipation of energy by plastic deformation (Fig. 10), while the work of separation decreases. Similar conclusions were also presented by Neimitz (2008)).

The side effect of the analysis is to demonstrate the influence of the constraint on the void growth process. It is confirmed that, for low stress triaxiality, which prevents cleavage fracture, the void volume fraction saturates and is not able to increase further. As a result, the fracture mechanism changes. The mechanism of nucleation, growth and coalescence of voids is replaced by plastic slip along the crystallographic planes. Such conditions can be found in the neighborhood of the specimen surface. In the middle of the specimen, the constraint changes and promotes void growth (Gałkiewicz, 2014). During the loading of the member crack, the stress triaxiality decreases and the area, where the void growth saturates and is unable to increase further, extends. 


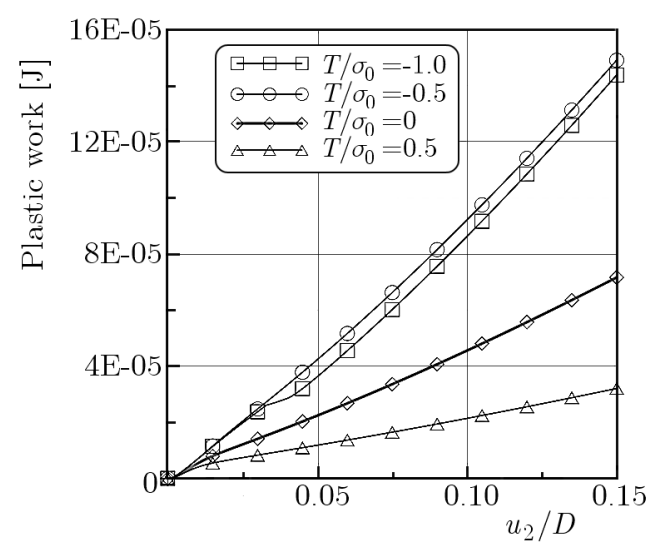

Fig. 10. Plastic energy consumed by the cell

\section{Acknowledgment}

The financial support from the Polish Ministry of Science and Higher Education under contract no. N N 501199640 is gratefully acknowledged.

\section{References}

1. AL-Ani A., HANCOCK J.W., 1991, J-Dominance of short cracks in tension and bending, Journal of Mechanics and Physics of Solids, 39, 1, 23-43

2. Barenblatt G.I., 1959, The formation of equilibrium cracks during brittle fracture: general ideas and hypotheses, axially symmetric cracks, Applied Mathematics and Mechanics (PMM), 23, $622-636$

3. Brocks W., Cornec A., Scheider I., 2003, Computational aspects of nonlinear fracture mechanics, [In:] Comprehensive Structural Integrity - Numerical and Computational Methods, Milne I., Ritchie R.O., Karihaloo B. (Eds.), Oxford: Elsevier, 3, 127-209

4. Cornec A., Scheider I., Schwalbe K.H., 2003, On the practical application of the cohesive model, Engineering Fracture Mechanics, 70, 1963-1987

5. Dugdale D.S., 1960, Yielding of steel sheets containing slits, Journal of Mechanics and Physics of Solids, 8, 100-108

6. Faleskog J., Gao X., Shin C. F., 1998, Cell model for nonlinear fracture analysis - I. Micromechanics calibration, International Journal of Fracture, 89, 355-373

7. GaŁkiewicz J., 2014, The simulation of void growth along curvilinear crack front, Key Engineering Materials, 598, 63-68

8. Gao X., Faleskog J., Shin C. F., 1998, Cell model for nonlinear fracture analysis - II. Fractureprocess calibration and verification, International Journal of Fracture, 89, 375-398

9. Gurson A.L., 1977, Continuum theory of ductile rupture by void nucleation and growth - Part I. Yield criteria and flow rules for porous ductile media, Journal of Engineering Materials and Technology, 99, 2-15

10. LI V.C., WARD R.J., 1989, A novel testing technique for post-peak tensile behaviour of cementitious materials, [In:] Fracture Toughness and Fracture Energy - Testing Methods For Concrete and Rocks, Mihashi H., Takahashi H., Wittmann F.H. (Edits.), Rotterdam: A.A. Balkema Publishers, 183-195

11. Neimitz A., 2008, The jump-like crack growth model, the estimation of fracture energy and JR curve, Engineering Fracture Mechanics, 75, 236-252 
12. O’Dowd N.P., Shit S.F., Dodds, JR. R.H., 1995, The role of geometry and crack growth on constraint and implications for ductile/brittle fracture, [In:] Constraint Effects in Fracture Theory and Applications, M. Kirk, A. Bakker (Edits.), 2, ASTM STP 1244, American Society for Testing and Materials, Philadelphia

13. Panasyuk W.W., 1968, Limit State of Brittle Solids Containing Cracks (in Russian), Kiev, Naukova Dumka

14. Park K., Paulino G.H., Roesler J.R., 2009, A unified potential-based cohesive model of mixed-mode fracture, Journal of the Mechanics and Physics of Solids, 57, 891-908

15. Scheider I., Brocks W., 2003, Simulation of cup-cone fracture using the cohesive model, Engineering Fracture Mechanics, 70, 1943-1961

16. Scheider I., Schodel M., Brocks W., Schonfeld W., 2006, Crack propagation analyses with CTOA and cohesive model: Comparison and experimental validation, Engineering Fracture Mechanics, 73, 252-263

17. Sorensen B.F., Jacobsen T.K., 2003, Determination of cohesive laws by the J integral approach, Engineering Fracture Mechanics, 70, 1841-1858

18. Turon A., Camanho P.P., Costa J., Davila C.G., 2006, A damage model for the simulation of delamination in advanced composites under variable-mode loading, Mechanics of Materials, 38, $11,1072-1089$

19. TVErgaArD V., 1981, Influence of voids on shear band instabilities under plane strain conditions, International Journal of Fracture, 17, 4, 389-407

20. Tvergandd V., Hutchinson J.W., 1992, The relation between crack growth resistance and fracture process parameters in elastic-plastic solids, Journal of Mechanics and Physics of Solids, 40, 6, 1377-1397

21. Tvergand V., Needleman A., 1984, Analysis of the cup-cone fracture in a round tensile bar, Acta Metallurgica, 32, 1, 157-169

22. Williams, M.L., 1957, On the stress distribution at the base of a stationary crack, ASME Journal of Applied Mechanics, 24, 111-114

23. XiA L., Shin C.F., 1995, Ductile crack growth - I. A numerical study using computational cells with microstructurally-based length scales, Journal of the Mechanics and Physics of Solids, 43, 2, 233-259

24. XiA L., Shiн C.F., 1995, Ductile crack growth - II. Void nucleation and geometry effects on macroscopic fracture behavior, Journal of the Mechanics and Physics of Solids, 43, 12, 1953-1981

Manuscript received March 6, 2014; accepted for print December 4, 2014 